\title{
Correction to: Deploying Personalized Oblivious Mobile Identity
}

\author{
Georgia Sourla and Evangelos Sakkopoulos [e
}

\section{Correction to: \\ Chapter "Deploying Personalized Oblivious Mobile Identity" in: M. Virvou et al. (Eds.): Knowledge-Based Software \\ Engineering: 2020, LAIS 19, https://doi.org/10.1007/978-3-030-53949-8_15}

In the original version of the book, the following belated correction has been incorporated:

In Chapter 15, the affiliation of author "Georgia Sourla" has been changed from "Scytales, Argyroupoli, Sweden" to "Scytales AB, Taby, Sweden".

The chapter and book have now been updated with the change. 